\title{
Article
}

\section{Advancing understanding of pinch-points and crime prevention in the food supply chain}

Soon, Jan Mei, Manning, Louise and Smith, Robert

Available at http://clok.uclan.ac.uk/23780/

Soon, Jan Mei ORCID: 0000-0003-0488-1434, Manning, Louise and Smith, Robert (2019) Advancing understanding of pinch-points and crime prevention in the food supply chain. Crime Prevention and Community Safety, 21 (1). pp. 42-60. ISSN 1460-3780

It is advisable to refer to the publisher's version if you intend to cite from the work. http://dx.doi.org/10.1057//541300-019-00059-5

For more information about UCLan's research in this area go to http://www.uclan.ac.uk/researchgroups/ and search for <name of research Group>.

For information about Research generally at UCLan please go to http://www.uclan.ac.uk/research/

All outputs in CLoK are protected by Intellectual Property Rights law, including Copyright law. Copyright, IPR and Moral Rights for the works on this site are retained by the individual authors and/or other copyright owners. Terms and conditions for use of this material are defined in the policies page.

\section{CLoK}

Central Lancashire online Knowledge www.clok.uclan.ac.uk

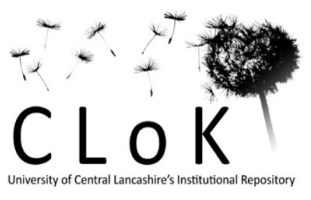




\title{
Advancing understanding of pinch-points and crime prevention in the
}

\author{
food supply chain
}

JAN MEI SOON¹, LOUISE MANNING² AND ROBERT SMITH

${ }^{1}$ International Institute of Nutritional Sciences and Applied Food Safety Studies, School of Sport and Wellbeing, University of Central Lancashire, Preston PR1 2HE UK

${ }^{2}$ Harper Adams University, Newport, Shropshire, UK TF10 8NB

${ }^{3}$ School of Business and Enterprise, University of the West of Scotland, Dumfries, DG1 4ZN UK

\section{Abstract}

From a crime prevention perspective, food crime remains a challenge. Whilst opportunity for crime can be reduced by implementing certain measures; and addressing the potential perpetrators, their possible actions and criminal behaviour, the trade-offs which occur in the food supply chain that motivate such activity, still remains complex. These heuristic factors have led, in this study, to the consideration of 'pinch-points' where crime could occur as a result of capability, opportunity, motivation, rationalisation and supply chain pressure. Pinch-points can be addressed using the Food Crime Countermeasures Framework (FCCF) conceptualised in this paper. We argue that conventional anti-fraud measures: detection, deterrence and prevention are essential to support food fraud risk assessments, as are continuous interventions and response strategies. The implementation of countermeasures that initially drive prevention and deterrence and where required, detection, intervention and response form the basis of our approach. This paper focuses on the United Kingdom (UK) however it should recognised that food crime is a global issue.

\footnotetext{
${ }^{1}$ Author for correspondence: Tel: +44(0)1772 894567; E-mail: jmsoon@ uclan.ac.uk.
} 
Keywords: continuous interventions; countermeasures; fraud; vulnerability

\section{Introduction}

Whilst the topic of this paper is not generally the subject of criminological discourse it is nevertheless a contemporary and patently problematic criminological issue which is currently manifesting at a practical level. It is thus important, from a crime prevention and reduction perspective to examine at this practical, operational level. Consequentially, this paper aims to contextualise and synthesise the specialist knowledge implicit within the literature of food crime with that of crime prevention and reduction and thus as a result broaden the focus of both literatures. Whilst this study implicitly refers to the United Kingdom (UK) it is a worldwide and a cross-national crime problem and the framework presented herein has utility too at a global level.

The overarching topic of this conceptual paper is that of 'pinch-points'

41 because it is within context that food crime is operationalised. The term "pinch42 point" has been used to variously across the supply chain, safe practice and 43 policing literature to describe 1) physical points or locations (Makwasha and 44 Turner, 2013); 2) the weakest necessary conditions for the problems to persist when considering problem orientated policing (Read and Tilley, 2000); 3)

46 strategic points in the supply chain such as bottlenecks where there is 47 sensitivity to disruption and/or limited capacity (Christopher and Peck, 2004); and 4) points of intervention (Weisel, 2003) such as where external pressure

49 can be applied e.g. regulatory pressure or stimulus (Yakovleva and Flynn, 50 2004); or where pressure can be applied to disrupt criminal activity (Chon, 51 2016). Pinch points can also occur as a result of supply chain pressure 
52 (Manning et al, 2017). Wolf and Hermanson (2004) argue that pressure is one

53 element of the "fraud diamond" model, the other three elements being 54 capability, opportunity and motivation. Indeed, trading in an environment where 55 there are differentiated global standards for animal welfare, environmental 56 protection and worker welfare standards can lead to pinch points. Manning et 57 al, (2017) argue that the existing model of the two-dimensional fraud diamond 58 is actually three dimensional and multifaceted when the socio-economic 59 dynamics of supply chain pressure should also be considered.

60 In summary, a pinch-point is the location at which intervention might be 61 expected to have the longest term of action and the widest impact (Read and 62 Tilley, 2000) and in the context of food crime the point where interventions take 63 place that will have the longest and widest impact on mitigating illicit behaviour.

64 In terms of types of crime associated with the food chain this paper is 65 considering inter-food supply chain crime i.e. criminal activity that occurs 66 between one discrete food supply chain and another, the legal and the illicit. 67 Conversely, intra food supply chain criminal activity is the criminal activity 68 that occurs between actors within an otherwise seemingly legitimate food 69 supply chain. To provide clarity the following definitions from Closs and 70 McGarrell (2004, p. 8) are used:-

71 - A supply chain is the combination of organisations and service providers 72 that manage the raw material sourcing, manufacturing, and delivery of 73 goods from the source of the commodities to the ultimate users.

74 - Supply chain management is the inter- and intra- organisational 75 coordination of the sourcing, production, inventory management, 
transportation, and storage functions with the objective of meeting the service requirements of consumers or users at the minimum cost. Farms are just one element of the supply chain that encompasses multiple actors and stakeholders. Indeed, farm crime can be considered in terms of criminal typology such as the urban marauder (Smith, 2010) exploiting often

81 weak levels of security and police activity in rural areas, organised criminal gangs (OCGs) that may involve a network of insider groups (such as farmers) as well as external actors who can pass on the illicit goods into wider markets and destinations (McElwee et al, 2017). Also of interest here is the farm as a defensible and thus safe space (Newman, 1972; Mawby, 2017). Traditionally, in the UK, farmers have been lax in engaging in crime prevention and crime reduction initiatives, albeit this is changing with the advent of the 'Fortress Farm' Concept' (NFU Mutual, 2017). The fortress farm concept suggests that as countryside criminals increase their activity on farms the farmers as a result feel under siege and are turning their existing farmyards into protected fortresses in

91 an effort to safeguard their property. Thus, the context in which farm, and wider food supply chain, crime is operationalised has an impact on the 'pinch-points' discussed herein. examine supply chain issues, including the importance of making trade-offs. concept within the food crime prevention literature. We then consider the issue of crime vulnerability and crime prevention weakspots. This leads us to 99 consider how to design appropriate crime prevention strategies. The paper 100 concludes with some relevant observations. 
102 Prior to discussing the concept of 'pinch-points' it is necessary to begin by 103 outlining the importance of developing an understanding of the supply chain 104 perspective because it is within this context that food crime is operationalised. 105 Illicit behaviour is a contemporary (but ancient) theme in food supply chains in 106 terms of academic research, industry awareness, and in emergent food related 107 organisational and supply chain literature. Illegal activity in food supply chains 108 is not only a discrete process operating in parallel to legal activities and supply 109 chains, but is also embedded within authorised, licensed and permitted 110 processes that have particular elements of opacity (see Gregson and Crang, 111 2017; Manning et al, 2017). Since the global financial recession of 2007-08,

112 McElwee et al, (2017) suggest that contemporary evidence from official reports 113 and the media shows an increase in food related criminal activity including food 114 adulteration, mislabelling of food, sheep theft, and trading in illegal halal meat. 115 However, the strategic decision by individuals or groups to engage in informal, 116 and criminal acts for financial gain is complex. It may be motivated by socio117 political factors, such as the UK Government's austerity programme where the 118 first fiscal and social measures were introduced in 2008. The impact of the 119 austerity programme on the food supply chain, drove for some organisations 120 the need to firstly be resilient, or in some cases to simply survive, and in some 121 instances individuals and organisations focused on motives of profit 122 maximisation and greed (Smith et al, 2017a).

123 The food supply chain is complex and involves both the farming sector 124 and food industries, therefore adopting a holistic approach is essential to 
125 combatting food supply chain crime. This paper makes a start by considering

126 the issue of 'pinch-points' that has been previously somewhat neglected by

127 criminologists in this context. Organisations within the chain do not sit in

128 isolation; they interact with external influences in their wider environment

129 (Winter et al, 2014). Supply chains are socio-economic networks with inter-

130 related strategies, activities, dynamic components (the products, processes

131 and technical knowledge employed) and structural elements such the key

132 actors involved including the retailer, farmer, manufacturers processor,

133 distributors and food service. Primary producers are the actors that provide raw

134 material, such as farms and aquaculture secondary producers (manufacturers

135 that enhance the value of raw materials, wholesalers, distributors) and tertiary 136 producers, retailers and food services (see Closs and McGarrell 2004; Borghesi

137 and Gaudenzi, 2013). Other factors include firstly the role and influence of 138 stakeholders such as investors, shareholders, insurers, certification bodies, 139 governments, policy makers and regulators, civil society, amongst others; 140 secondly the complexity of the relationships formed between stakeholders, 141 thirdly the climate of the relationships in terms of collaborative or conflicting 142 characteristics of association, and lastly the type of goals each actor develops 143 (Closs and McGarrell, 2004; Borghesi and Gaudenzi, 2013). This begs the 144 question as to the factors that have led to this reported rise in food related 145 criminal activity both at farm level, and across the wider supply chain and how 146 in some circumstances illicit behaviour is rationalised by perpetrators from 147 being the exception to becoming the norm. We investigate these factors which 148 are arguably influenced by multiple trade-offs within the food supply chain.

149 Trade-offs occur because in a given situation neither the decision- 
maker, nor wider society can have everything they want so as a result they

151 have to compromise in some way (Campbell and Kelly, 1994). A trade-off is a

152 mediated form of decision-making or compromise, and this type of decision-

153 making is ubiquitous at farm level when land is managed with multiple strategic

154 and operational objectives (Klapwijk et al, 2014). Consumer trade-offs occur

155 when they are willing to trade one attribute for another e.g. quality for price

156 (Luce et al, 1999). Trade-offs occur at multiple levels including field, enterprise,

157 farm, landscape or supply chain (Table 1).

158 Take in Table 1

Research on trade-offs especially with multiple attributes and/or

160 collective decision-making has considered the trade-off between time and cost

161 (Feng et al, 1997); time, cost and quality (Monghasemi et al, 2015); speed and

162 accuracy (Häubl and Trifts 2000: Franks et al. 2003; Dane and Pratt, 2007);

163 accuracy and effort (Johnson and Payne, 1985; Bettman et al, 1990; Häubl

164 and Trifts, 2000; Boulis et al. 2003; Gigerenzer and Gaissnaier, 2011);

165 accuracy and informativeness i.e. accepting errors in return for securing more

166 informative judgments (Yaniv and Foster, 1995); cost and risk (Kerstholt, 1994);

167 and finally benefit and harm (O'Connor et al, 2003).

In addition, time pressure is a frequent element of trade-offs. Time

169 pressure is driven by deadlines when the time available may be perceived as

170 too short to make a decision. Multiple studies have investigated this

171 phenomenon (Huber and Kunz, 2007). Time pressure, may also lead to a

172 negative emotional response (Maule et al, 2000) which then affects decision-

173 making. Luce et al, (1999, p. 144) define emotional trade-off difficulty as "the 
level of subjective threat a decision-maker associates with an explicit trade-off between two attributes". Thus positive (benefit) and negative emotion (fear, harm, anxiety, threat, challenge, concern, uncertainty) and specific emotional goals (such as protecting self-esteem, maintaining a moral value or ideal) have an impact on both cognitive appraisal and decision-making. Therefore, tradeoffs occur at occur multiple, complex and interwoven levels and the trade-off between legality and illegality is only one of a number of decisions that supply chain actors have to take.

Humans adapt their decision-making behaviour to a given situation, or environment, often seeking to reduce the amount of associated cognitive effort required to reach the decision (Shugan, 1980; Häubl and Trifts 2000). This can occur as a conscious response or as an unconscious cognitive strategy. Thus arguably decision-making is a situated event influenced by a number of factors. Prendergast (2002) suggests that the trade-off of risk versus incentive is influenced by how risk is determined e.g. risk as measured by volatility or variance of returns by the executive, whereas for farmers it is the variance of profits or variance of yield in a given crop cycle.

In this context a food crime threat can be considered to be an agent that arises from fraud, or perpetrators taking advantage of the market opportunities to substitute, or deceive, as a result of weather events, harvest failure etc. that can cause loss or harm to individuals and/or organisations. Profit maximisation in the agricultural sector is contextualised by characteristics of constant uncertainty and risk of failure due to weather, animal disease etc. and many farming organisations have limited opportunities in terms of growth orientation 
and business expansion (Smith et al, 2017b). We now turn to examine these

199 pinch-points in the supply chain that give rise to the environment where crime

200 could occur.

\section{Appreciating the importance of pinch-points in the supply chain.}

To achieve a greater understanding of the topic it is helpful to map these pinch-points. As a process, pinch-point mapping involves identifying potential

204 bottlenecks and threats and manipulating and managing those points to ensure 205 effective control of resources in order to meet demand (Pil and Holweg, 2006). Moreto and Clarke (2013) in their research on transnational illegal markets in endangered species highlight that crime is situational and by directing preventive measures at pinch-points this will deliver the best results in reducing

209 the potential for criminal activity. Furthermore, different crimes will have 210 different pinch-points.

211 Borghesi and Gaudenzi (2013) considered four types of supply chain risk:

212 1) market risk; 2) process risk; 3) supplier and environmental risk; and 4) the 213 risks associated with transparency and information visibility. For a retailer, the 214 degree of risk associated with a given supply chain actor is mediated by 215 whether the individual or business of interest has either a given monopoly in 216 terms of the product or service they supply i.e. they are non-substitutable or 217 alternatively they can be easily substituted e.g. farmers all providing the same 218 commodity. Traditional supply chain responses to managing and mitigating risk 219 include using insurance, greater information sharing or outsourcing risk to other 220 supply chain actors (Olson and $\mathrm{Wu}, 2011)$. Therefore, organisations can be 221 driven by their shareholder or insurer demands to quantify, manage and where 
222 possible mitigate their risk profile. As a result, retailers, manufacturers or food

223 service may seek to adopt a systems based approach to manage, mitigate or 224 outsource risk.

225 Within this market context, there are multiple pressure factors that can drive 226 illicit activity in food supply chains including rapid development of systems, 227 logistics and technology, asymmetry in information flow, data swamping and 228 opacity; market competition and resource scarcity, inadequate policy and 229 market governance, lack of regulatory and market sanctions, and ultimately low 230 probability of discovery (Charlebois et al, 2016; Manning et al, 2016; Manning, 231 2016; Marvin et al, 2016; Manning et al, 2017). This pressure can create a 232 series of pinch-points at informal interfaces; formal and visible interfaces; and 233 invisible interface(s) where differentiation in stakeholder approaches to supply 234 chain risk, organisational goals and objectives leads to trade-offs and thus give 235 rise to illicit behaviour. Taking a transactional approach and simply developing 236 formal risk prevention strategies (countermeasures or preventive measures) is 237 a welcome start but not enough to address the challenge of illicit behaviour and 238 thus address the pressures and opportunities. Countermeasures are intended 239 to reduce criminal opportunity in food supply chains (Spink et al, 2015). The 240 implementation of countermeasures will not only have a preventive aspect in 241 terms of preventing an incident and also making it more unlikely in the first 242 place, but should an incident occur appropriate countermeasures will lessen 243 too the impact of a given incident (Mitenus et al, 2014). Capability, motivation, 244 rationalisation, derived value propositions, and regulatory and market 245 incentives for illicit behaviour also need to be considered when developing 246 crime prevention strategies (Manning et al, 2016; Manning et al, 2017). 
The actualisation of this pressure on capability, opportunity and motivation

248 dynamics can be seen through the lens of recent global food scandals such as

249 the 2013 European horsemeat scandal (Smith and McElwee, 2017); the 2017

250 meat fraud scandal in Brazil (Manning et al, 2017), and the 2017 fipronil in eggs

251 and composite products scandal in Europe (Kowalska et al, 2018). The lack of

252 early and harmonised regulatory intervention in the fipronil scandal resulted in

253 an incident affecting 56 countries (RASFF Portal, 2018; RASFF 2018;

254 Kowalska et al, 2018). A number of contextual factors impact on criminal

255 behaviour such as pressure, resource allocation and ownership, greed,

256 economic inferiority, need and power relations.

\section{Situating pinch-points in the food crime prevention literature.}

259 Supply chain power is driven by the degree of power localisation or 260 conversely distribution and each actor's relative control of or access to 261 resources and capital assets. Thus the risk of illicit behaviour is situational and 262 is framed by power structures and other socio-economic factors. Successful 263 modes of food crime in terms of the degree of financial gain, or their impact in 264 the case of food defense (ideological food crime such as terrorism focused on 265 the food supply chain), reflect on the quality of execution and at what point, or 266 even if, detection actually occurs (Manning et al, 2017). The use of a pre267 requisite programme to minimise, and where possible eliminate, the likelihood 268 of an unintentional food safety incident is well established in the food supply 269 chain through the hazard analysis critical control point (HACCP) approach. The 270 alternative, i.e. the development of a countermeasures programme to minimise, 
271 or where possible eliminate, the likelihood of a food crime threat is less well 272 determined.

273 In the wake of the 2013 Horsemeat Scandal, the Elliott Review determined 274 that a national food crime prevention framework was essential to prevent a 275 future food crime incident (Elliott Review, 2014). Preventive measures, 276 deterrence and/or a lack of motivation to conduct food crime will also have 277 influence. Countermeasures that address food crime vulnerability can be 278 grouped into four categories: detection, deterrence and prevention and 279 disruption (Spink et al, 2015; Spink et al, 2016; Soon and Manning, 2017; van 280 Ruth et al, 2017). Detection measures can identify the activities associated with 281 food crime, whilst deterrence includes the measures that focus on a specific 282 type of perpetrator and their activities. Deterrence can be described as 1) the 283 inhibition of opportunity and perpetrator activity as a result of concern over the 284 personal consequences to themselves as a result of taking an action or the 285 maintenance of appropriate preventive measures, or 2) countermeasures that 286 discourage their activity (e.g. concern that the attack will fail). Prevention in this 287 context concerns the resources employed to minimise the potential for a food 288 crime incident to occur and ensure disruption mechanisms to address any 289 activity if it occurs. Kirby and Penna (2010) describe prevention as those 290 interventions that stop an incident especially where they change a process or 291 an environment in "a sustainable manner". In contrast Kirby and Penna (2010, 292 p. 205) define disruption as, "a more flexible, transitory, and dynamic tactic, 293 which can be used more generally to make the environment hostile ... [breaking 294 up] the offender's networks, lifestyle and routines". Disruption tactics often align 
295 to a prevention framework, thus serving as a deterrent through inhibiting 296 opportunity and reducing motivation to commit a crime (Kirby and Nailer, 2013). 297 Spink et al, (2017) recommend that in order to address the root cause of 298 food crime, in this instance fraud, food science and technology should 299 encompass social science, business and understanding of criminology. We 300 concur with this holistic approach using learning from a range of disciplines. To 301 further develop the countermeasures approach advocated by Elliott, Manning 302 and Soon (2016) compared and contrasted six existing food crime risk 303 assessment (FCRA) models in terms of their aims, mechanisms of operation 304 and practicalities of use. The risk assessment models were: threat analysis 305 critical control point (TACCP), vulnerability assessment and critical control point 306 (VACCP), the CARVER+SHOCK tool, the food protection risk matrix (Spink and 307 Moyer, 2011), and the United States Pharmacopeial (USP) preventive food 308 fraud management system. These operate at manufacturing and wider supply 309 chain level rather than being farm focused. Additional models are being 310 developed for food fraud vulnerability self-assessment including the SSAFE 311 model (van Ruth et al, 2017).

312 The ability to quantify the likelihood of a threat or vulnerability in a given 313 situation is influenced by the degree of adoption of countermeasures and their 314 effectiveness (Manning and Soon, 2016). Thus whilst FCRA is obviously of 315 value, the preventive benefit to organisations is limited. The output from FCRA 316 needs to be reviewed in line with any emerging or new threats otherwise the 317 risk assessment phase does not translate into an effective, and dynamic food 318 crime countermeasures framework (FCCF). The development of the FCCF is 319 essential to embed preventive measures, identify relevant sources of 
320 intelligence on changing status of risk, detect illicit activity, and ensure timely

321 and appropriate responsive action and a countermeasures' continuous

322 improvement strategy. Therefore, three factors: detection, deterrence and

323 prevention can be drawn together at regulatory, supply chain or individual

324 business level to underpin a FCCF of integrated risk assessment and

325 implementation of countermeasures that initially drive prevention and 326 deterrence and where required, detection, intervention and response (Figure 327 1).

\section{$328 \quad$ Take in Figure 1}

329 Horizon scanning is a useful crime prevention tool. Roy et al, (2014), albeit not 330 in a crime context, describe horizon scanning, as the systematic examination 331 of future potential threats and opportunities, resulting in the prioritisation of 332 threats and their effective management. Therefore, horizon scanning has the 333 potential to act as an early warning system, initiating prompt discussion and 334 then decision making about threat mitigation (Stanley et al, 2015 p. 553).

335 Horizon scanning can be considered as a systematic way of considering 336 evidence about future trends and scenarios in order to determine whether an 337 organisation is adequately prepared for potential threats and has implemented, 338 or can readily adopt, means for their appropriate countermeasure control. 339 Effective horizon scanning for food crime is a foundation for a FCCF i.e. 340 considering intelligence from a range of sources, be it economic, social or 341 environmental, in order to effectively map possible criminal scenarios 342 associated with the materials and products that the organisation procures, 343 produces and sells, in order to accurately identify the potential threat, the 
344 controls required and the mechanisms for updating such assessments if the 345 evidence (intelligence) changes in the future.

346 During the mapping process weak areas, pinch-points or hotspots that 347 are vulnerable to food crime at specific stages in food supply chains or networks 348 can be determined. Detection, mapping and prevention activities can only be 349 developed to address known issues or activities, making TACCP and VACCP 350 of limited value with regard to emerging crime risk or entrepreneurial, 351 enterprising, situational crime risk that is reactive, responsive and specific to an 352 organisation, the products it produces and the associated supply chain (Soon 353 and Manning, 2017; McElwee et al, 2017; Smith, 2017). Van Ruth et al, (2017) considered food supply chain vulnerability to fraud and based their conceptualisation on the elements of opportunity (suitable target in terms of time, space and technical opportunities), motivation (the economic drivers, supply and pricing, value added product attributes where the potential to substitute an inferior product has the potential for a higher financial 359 gain, economic environment and financial strains and culture and behaviour 360 including business strategy and business culture) and the control measures 361 (technical and managerial measures) linking their work to the routine activity 362 theory developed by Cohen and Felson (1979).

363 Guardians are the individuals operating at national, supply chain or 364 individual business levels (Spink et al, 2015) that have the knowledge, skills 365 and understanding to implement a FCCF. Although guardians do not have to 366 have a specific intent to watch over food products and services, they can act 367 as guardians whilst carrying out their roles as managers or handlers (Hollis and 368 Wilson, 2014). However, vulnerability can still occur even in the presence of a 
369 capable guardian. This is where guardianship activity can be further enhanced

370 by monitoring activities. The combination of available / visible guardians who

371 are also monitoring the food products / process throughout the supply chain

372 could provide a stronger deterrent effect (Reynald, 2009; Hollis and Wilson,

373 2014). Those individuals or teams developing FCCF need to recognise that the

374 adoption of universal, general countermeasures based on historic threats as a

375 'catch all approach' to preventing and where required managing food crime is

376 of limited value in addressing illicit behaviour that is caused by supply chain 377 pressure. This is because the drivers of illicit behaviour and associated 378 opportunity, rationalisation, capability and motivation, and derived value 379 proposition are situational and transitory.

Situational crime risk and the means to predict its occurrence has been 381 explored within criminology and contemporary food literature (Perline and 382 Goldschmidt, 2004; McGloin et al, 2011; Manning and Soon, 2016). Situational 383 crime risk factors include factors such as supply chain pressure, power 384 asymmetry, type of corporate culture, the work environment and can have a 385 multiple, compounding impact (Perline and Goldschmidt, 2004: Carson and 386 Bull, 2003). Situational crime risk can be mitigated by strengthening 387 environmental resilience (Clapton, 2014) especially by increasing the 388 associated personal risks and difficulties associated with the crime and 389 alternatively reducing the potential personal rewards of committing a crime 390 (Clarke, 1995; Spink and Moyer, 2011).

391 The concept of crime prevention through environmental design is 392 nothing new as the design of physical space has long been identified as being 393 important in understanding and mitigating criminal behaviour (Newman, 1972). 
394 Newman proposed that defensible space can be created when the physical 395 space is structured in a way that reinforces the social structure that defends 396 itself i.e. a farm or factory design could in itself help or hinder the social culture 397 of the organisation in which people work and their psychological engagement 398 with the space itself. This idea of defensible space is developed by van Ruth et 399 al, (2017) into a concept of hard controls (physical and technical 400 countermeasures) and soft controls which reflect the managerial controls that 401 are in place. Appropriate countermeasures that are based on the concept of 402 defensible space can be adopted in a preventive approach to crime in the food 403 supply chain. Here we take this further to consider Newman's four themes of 404 defensible space and these have been adapted in this conceptual research to 405 considerations of a food supply chain environment: van Ruth et al, (2017) 406 differentiate between external environment that consists of three levels 1) the 407 direct supplier and customers; 2) the wider supply chain and industry network 408 and 3) the international and national environment as opposed to the internal 409 environment within the business. The four elements discussed here are 410 territoriality, surveillance, image and milieu or juxtaposition:

411 - Territoriality - creates a sense of legitimate and illegitimate access to 412 space i.e. identifying the legitimate allocation of space to those who are 413 approved to work in the area and those who should not have access. Food 414 industry protocols that address territoriality will assure that appropriate 415 people are in a given space (production line, factory), wear colour coded 416 protective clothing by location as this will create a visual territoriality that 417 should prove a deterrent to illicit individuals entering that space who would 418 be readily identified if they are not in appropriate clothing. Whilst territoriality 
can be addressed by protocols in processing, storage and defined spaces

420 such as farmyard areas, it proves more problematic at the field level where

421 in the UK access often cannot be limited or prevented. Further if the 422 perpetrators of crime are not outsiders or strangers, but are instead 423 members of the community such as other farmers and/or professional rural 424 offenders with legitimate reasons for access to a given location then 425 legitimacy of access will have less influence on crime prevention (Mawby, 426 2017). Therefore this option to mitigate food crime can only be used in 427 certain situations.

428 - Surveillance - designing the physical space in a way that assists legitimate 429 users to observe the behaviours of both employees and visitors e.g. 430 temporary workers, service engineers, contract cleaners etc. Again this 431 approach is of value in a bounded work environment where territoriality and 432 surveillance can combine, but harder to implement at the field level;

433 - Image - a sense that the physical space is well cared for and developing 434 preventive measures that reduce the visual appearance that areas of the 435 factory, farm, distribution centre or manufacturing site are remote, little 436 used, or not regularly visited; and

437 - Milieu or juxtaposition - which, in the context of a food supply chain, 438 describes the image, natural surveillance and territoriality of other 439 businesses that interface with the organisation's space. This element 440 reflects that other businesses in the supply chain may either not be 441 addressing defensive space or may undertake opaque practices or lack 442 transparency. 
443 The example given here is one of defensive space in the physical context. The

444 other area of defensive space is more ethereal, such as data storage, data

445 exchange and cyber-related space. Cybersecurity can be described as the

446 countermeasures taken to protect a computer system and associated storage

447 clouds or individual appliance against an intentional malicious target attack

448 and/or unauthorised access and unintentional or accidental access.

449 Cybersecurity countermeasures include, but are not limited to, developing 450 cybersecurity policies and procedures, undertaking focused FCRA, adopting

451 training and awareness sessions for staff commensurate with an individual staff

452 member's responsibilities and developing soft or hard controls such as specific

453 software, firewalls, technologies etc. that can protect the organisation's cyber 454 environment and their electronic assets (Manning, forthcoming).

455 However, preventive environmental design to mitigate food crime risk is of 456 limited benefit if there is high-level insider complicity i.e. the involvement of the 457 business owner, management or employees in criminal activity in illegal 458 practices such as covert operations by running out of hours processing known 459 only to a select few (McElwee et al, 2017). Therefore, consideration of the 460 impact of the processing environment and the wider supply chain environment 461 is of value, but it cannot address all potential threats and is not as a result a 462 zero risk approach. However the theory of defensive space does lend itself to 463 adoption within an overarching FCCF.

464 In this respect, the concept of hurdles is of interest. Spink et al, (2015) define 465 hurdles in the context of food crime prevention approaches as the transactional, 466 formal system components that reduce opportunity for food crime by either 467 assisting detection or proving to be a deterrent. These would include on-line 
468 monitoring and verification activities in the wider supply chain such as audits

469 and product sampling. Verification is discussed in more detail later in the paper.

470 Thus a hurdle gap can be described as a vulnerability to food crime where such

471 mitigation activities are not in place, or alternatively are in place, but are not 472 effective.

\section{Determining crime vulnerability and identifying crime prevention}

\section{weakspots}

Food criminals are clandestine, stealthy, and actively seek to avoid detection (Spink, 2011). According to the Centre for the Protection of National 478 Infrastructure (CPNI, 2013), the majority of insider criminal activity in 479 organisations was carried out by permanent staff ( $88 \%)$, with only $7 \%$ of cases 480 involving contractors and 5\% involving agency or temporary staff. Individuals 481 who had worked for their organisation for less than 5 years represented $60 \%$ of 482 cases and $49 \%$ of cases were by perpetrators aged between 31 and 45 . More 483 males (82\%) were involved in insider activity compared to females (18\%). 484 These data were derived from 120 UK-based insider cases from both public 485 and private organisations from a range of industry sectors, not just food, where 486 financial gain was the single most common primary motivation (47\%), ideology 487 (20\%), desire for recognition (14\%) and loyalty to friends, family or country 488 (14\%). This literature and other sources lends itself to categorising food criminal 489 according to type (see Spink and Moyer, 2013; Manning et al, 2016; PAS, 96: 490 2017) and by inference developing appropriate preventive strategies.

491 Crime vulnerability is the extent to which an individual, organisation, supply 492 chain or national food system is at risk from, or susceptible to, attack, emotional 
493 injury or physical harm, or damage from intentional illicit activity (Manning and

494 Soon, 2016). Vulnerability can be assessed, using input from legal, intelligence,

495 medical, scientific, economic, and political sources, to determine the scientific,

496 economic, political, and social circumstances of a country in order to quantify

497 the degree of threat and to set priorities for resources (Manning et al, 2005;

$498 \mathrm{WHO}, 2002)$. Vulnerability ranking is not static and needs to be routinely

499 reassessed to ensure that the ranking and prioritisation of crime risk remains

500 appropriate and that suitable countermeasure(s) continue to be in place.

501 McElwee et al, (2017) argue that in order to mitigate the potential for food crime

502 in the supply chain two approaches can be followed: firstly to design food supply

503 chains with built in risk-tolerance to crime and secondly to have appropriate

504 strategies in place to contain the damage once an undesirable event has been

505 identified. The magnitude of food crime risk (and to whom) will depend on the

506 likelihood and severity of each type of incident and the degree of 507 implementation of preventive and mitigation measures which can also be

508 affected by the efficacy of guardians and hurdles (Spink et al, 2015). Thus as 509 previously outlined in this paper there is no silver bullet of solutions to address

510 food crime instead holistic, situation-specific product and process crime

511 prevention strategies need to be adopted.

Designing appropriate crime prevention strategies

514 Regulators seek to reduce illegal activities either though punitive command

515 and control measures, prosecution and detection systems or alternatively via 516 preventative or deterrence measures such as awareness education and 517 enterprise support (Smith et al, 2017b). Alternatively, market orientated or 
518 supply chain approaches need to drive a crime prevention strategy based on

519 reduced opacity and more transparency and access to information in the supply

520 chain (the milieu). Supplier monitoring protocols need to include not only

521 product related procurement activities but also ethical codes of conduct,

522 integrity screening and whistleblowing protocols (van Ruth et al, 2017),

523 standard reference checks, financial status checks, and consideration of the

524 supplier's surge capacity and flexibility i.e. the ability to deliver increased

525 quantities at short notice, if required (Beil, 2009). A financial status check can

526 be incorporated into a suppliers' ranking and performance weighting and the

527 scoring system that can highlight and reflect financial risk associated with a

528 given supply base. This data will support FCRA that focuses on identifying the

529 suppliers who could be subject to the supply chain pressures described earlier

530 in this paper e.g. failed harvest, volatility in commodity price (wheat, milk, meat)

531 etc. and as a result be more likely to undertake illicit activities. These "high-risk"

532 suppliers can then be tracked and monitored. Price is one of the most important

533 factors used in supplier selection, but it is critical to ensure that the objectivity

534 of assessing product integrity and food crime risk is not lost in a purely risk:

535 financial reward; or time versus accuracy trade-off.

536 Forensic accounting has been adopted as a food crime countermeasure 537 especially to identify "false" suppliers (Power, 2013). Traceability tests and

538 second party and third party supply chain audits will provide more information

539 for focused forensic accounting and combined audits can be developed (Figure 540 2).

$541 \quad$ Take in Figure 2 
Indeed, it was a recommendation of the Elliott Review (2014) that the UK

543 government should "support the work of standards owners in developing

544 additional audit modules for food fraud prevention and detection incorporating

545 forensic accountancy and mass balance checks." Traceability protocols adopt

546 as a minimum the regulatory one step backward and one step forward tracking

547 and trace principle (EU Regulation No. 178/2002) or market protocols can

548 require traceability throughout from field to fork and the reverse too in a given

549 supply chain. However, with multiple ingredients used to make composite

550 products, and lengthy and complex food supply chains traceability can prove

551 difficult in practice. Additionally, if an individual business within the supply chain

552 deliberately and unanimously decides to behave illicitly, they can choose to

553 circumvent orthodox supply chain traceability countermeasures, controls and

554 monitoring. Therefore the value of developing a traceability countermeasures

555 is the promotion of food integrity and developing an open transparent supply

556 network. Procedural controls for traceability in themselves are not enough to

557 ensure consistent compliance and prevent the opportunity for illicit activity.

558 Further actions are needed including an effective verification (or surveillance)

559 programme that ensures that the controls are in place and adequate.

560 The process of food production involves discrete production stages from

561 farm to fork i.e. during growing, harvesting / slaughtering / catching of primary

562 products, primary processing, secondary processing of food / food ingredients,

563 packaging, labelling, storage and dispatch. These are all pinch-points where

564 food crime activities could occur. At the manufacturing stage specifically, 565 countermeasures need to be adopted to address the process vulnerabilities 566 that can provide opportunity for food crime earlier in the supply chain. 
or tampering with processes can be minimised via limited accessibility through

production equipment and where needed re-engineering of equipment to

571 prevent access e.g. covered conveyors, use of sight glasses, zoning (place)

572 and creating a buddy-system to limit lone workers at high-risk processes such

573 as use of expensive ingredients, or for recipe use where such information is

574 deemed confidential. Tracer ingredients can be added to high value food so

575 that potential counterfeit product can be readily identified in production and post

576 packing. Further supply chain preventive countermeasures include numbered

577 and tamper-proof seals on delivery vehicles and bulk storage silos, stock

578 control measures such as computerised fill level equipment which relay the

579 information back to central computerised systems, reduced electronic access

580 to specific physical zones which are deemed high-risk via fingerprint

581 technology, codes and passwords (PAS 96, 2017) password protection of

582 computer terminals and electronic process management systems etc.

584 is effective include substitution profit assessments, suppliers' ranking and 585 ongoing performance monitoring, risk rating of likelihood of perpetrators to 586 conduct activities, assessments to determine the likelihood of detection,

587 severity or impact of practices, consideration of the effectiveness of preventive 588 countermeasures and other factors that influence the risk of food crime such as 589 history of occurrences, seasonality, and market prices. The formal FCCF 590 systems, being visible and auditable, provide objective evidence to internal and 591 external stakeholders of the organisation's commitment to combatting food 
592 crime (Power, 2013). However this approach does not, according to Power,

593 build the soft knowledge required in terms of inspector skills to interpret audit

594 results. This means that a new type of balanced score card of soft, culture-

595 based risk factors also needs to be developed so that it can be effectively

596 verified. This development is worthy of further study and empirical research.

597 Assessing the efficacy of the FCCF encompasses both the technical areas

598 of responsibility within the food supply chain as equally as the administrative

599 areas of responsibility, so food auditors (food crime / fraud assessors) need to

600 work hand in hand with appropriately trained accountants, purchase ledger

601 administrators etc. The consistency of records and documentation can be

602 assessed via processes such as forensic accounting, and mass balance testing

603 for discrete batches allows unusual and inappropriate trends to be identified.

604 Market knowledge is essential to undertake this assessment effectively 605 especially because as described in this paper the risk is situational and 606 dynamic.

607 Verification through documentation review and classical food supply chain 608 auditing provides the food crime auditor with a range of evidence or audit 609 observations, which can be both qualitative, e.g. interviews, observations and 610 records or quantitative and based on measurement and test. System failure can 611 occur through people (human failure), process failure and place (i.e. design) 612 that provides opportunity for perpetrators to commit food crime. Therefore 613 verification activities need to include all of these areas in their scope.

614 The work of Newman has been introduced here and combined with the 615 literature from food supply and food crime risk identification and mitigation in a 616 novel approach. The need to address pinch-points and seek to prevent criminal 
617 activity occurring requires the translation of the theory of defensive space from

618 a previously urban-centric setting to one that reflects rural crime prevention too.

619 Crime in the food supply chain is not victimless, as the cost of such criminal 620 activity is ultimately met by food consumers. Further food consumers are being 621 misled, misinformed and cheated when such criminal activity occurs. Mawby 622 (2017) argues that crime prevention need to focus on locations where crime 623 most commonly occurs, defined here as pinch-points, rather than exclusively 624 on the circumstances that influence offending. It is important to state that 625 defensive space is posited here not just in terms of localised guardians and 626 physical hurdles, but for the food supply chain as a whole in terms of symbolic 627 hurdles and cyber-based hurdles rather than how the theory has historically 628 been used in wider criminological literature. For example further research work 629 could be undertaken to develop a food supply chain based "secured by design" 630 (SBD) approach to identify pinch-points and then a strategy of combined 631 activities to prevent crime from occurring.

632

\section{Conclusion}

This conceptual paper has developed our collective knowledge on how

635 an understanding of pinch-points and the FCCF presented advances our 636 understanding of the holistic nature of contemporary crime prevention 637 techniques used in the food supply chain. Conventional anti-fraud measures: 638 such as detection, deterrence and prevention are essential to support FCRA, 639 as are continuous interventions and response strategies. The implementation 640 of countermeasures that initially drive prevention and deterrence and where 641 required, detection, intervention and response form the basis of our approach. 
642 Pinch-points are not dissimilar to vulnerability points. Identification of pinch643 points and applying intervention strategies within the food supply chain - will

644 provide positive impact in reducing food crime. One way to address the pinch645 points is via the FCCF. In addition to the conventional deterrence, detection 646 and prevention methods, the FCCF emphasizes a circular or a feedback mechanism to ensure continuous interventions are successfully implemented. The countermeasures cover a range of potential pinch points and vulnerabilities or can be targeted measures that act against unique risks and perpetrators. The situational aspects of crime, often driven by trade-offs, in the food supply

651 chain means that holistic mechanisms need to be developed that address both 652 social aspects of rationalisation and also motivational economic aspects of opportunity and capability and the potential for such crimes to go undiscovered.

\section{References}

655

656

657

658

659

660

661

662

663

664

665

666

667

668

669

670

671

672

673

674

675

676

677
Beil, D. 2009. Supplier selection. Available at: http://wwwpersonal.umich.edu/ dbeil/Supplier_Selection_Beil-EORMS.pdf. accessed 2 January 2018.

Bettman, J.R., Johnson, E.J. and Payne, J.W. (1990) A componential analysis of cognitive effort in choice. Organ. Behavior Human Decision Processes.Vol. 45, pp 111-139.

Borghesi, A. and Gaudenzi, B. (2013) Operational risk and supply chain risk management. In Risk Management (pp. 117-137). Springer Milan.

Boulis, A., Ganeriwal, S. and Srivastava, M.B. (2003) Aggregation in sensor networks: an energy-accuracy trade-off. Ad hoc networks, Vol. 1, No. 2, pp 317-331.

Campbell, D.E. and Kelly, J.S. (1994) Trade-off theory. The American Economic Review, Vol. 84, No. 2, pp 422-426.

Carson, S. and Bull, R. (2003), Handbook of Psychology in Legal Contexts, John Wiley \& Sons. 
Charlebois, S., Schwab, A. Henn, R. and Huck, C.W. (2016) Food fraud: An exploratory study for measuring consumer perception towards mislabeled food products and influence on self- authentication intentions. Trends in Food Science \& Technology, Vol. 50, pp 211-218.

Chon, K.H.S. (2016) Cybercrime precursors: towards a model of offender resources. Available at: https://openresearchrepository.anu.edu.au/handle/1885/107344 accessed 2 January 2018

Cohen, L.E. and Felson, M. (1979) Social change and crime rate trends: A routine activity approach. American Sociological Association, Vol. 44, pp 588608.

Christopher, M. and Peck, H. (2004) Building the resilient supply chain, International Journal of Logistics Management, Vol. 15, No. 2, pp 1-13.

Clapton, W. (2014) Risk and Hierarchy in International Society: Liberal Interventions in the Post-Cold War Era. Palsgrave Macmillan

Clarke, R.V. (1995) Situational Crime Prevention, Crime and Justice Vol. 19, Building a Safer Society: Strategic Approaches to Crime Prevention (1995), pp 91-150

Closs, D.J. and McGarrell, E.F. (2004) Enhancing security throughout the supply chain. Washington, DC: IBM Center for the Business of Government. Available at: https://www-

03.ibm.com/procurement/proweb.nsf/objectdocswebview/filesupply+chain+se curity+white+paper+and+assessment+guide+april+2004/\$file/supply+chain+s ecurity+white+paper+and+assessment+guide+april+2004.pdf (accessed on 2 January 2018)

CPNI Centre for the Protection of National Infrastructure. (2013). CPNI insider data collection study: Report of main findings. Available at:

http://www.cpni.gov.uk/Documents/Publications/2013/2013003insider_data_collection_study.pdf. accessed 2 January 2018

Dane, E. and Pratt, M.G. (2007) Exploring intuition and its role in managerial decision making. Academy of management review, Vol. 32, No. 1, pp33-54.

Elliott Review. (2014). Elliott Review into the integrity and assurance of food supply networks - Final report A national food crime prevention framework. HM Government, July 2014 London.

EC 178/2002. 2002. Regulation (EC) No 178/2002 of the European Parliament and of the Council of 28 January 2002 laying down the general principles and requirements of food law, establishing the European Food Safety Authority and laying down procedures in matters of food safety. Official Journal of the European Communities L31/1: 1-24. 
Feng, C.W., Liu, L. and Burns, S.A. (1997) Using genetic algorithms to solve construction time-cost trade-off problems. Journal of computing in civil engineering, Vol. 11, No. 3, pp184-189.

Franks, N.R., Dornhaus, A. Fitzsimmons, J.P. and Stevens, M. (2003) Speed versus accuracy in collective decision making. Proceedings of the Royal Society of London B: Biological Sciences, Vol. 270, No. 1532, pp 2457-2463.

Gigerenzer, G. and Gaissmaier, W. (2011) Heuristic decision making. Annual review of psychology, Vol. 62, pp 451-482.

Gregson, N. and Crang, M. (2017) Illicit economies: customary illegality, moral economies and circulation. Transactions of the Institute of British Geographers, Vol. 42, No. 2, pp 206-219.

Häubl, G. and Trifts, V. (2000). Consumer decision making in online shopping environments: The effects of interactive decision aids. Marketing science, Vol. 19, No. 1, pp 4-21

Hollis, M.E. and Wilson, J.M. (2014) Who are the guardians in product counterfeiting? A theoretical application of routine activities theory. Crime Prevention and Community Safety, Vol. 16, No. 3, pp 169-188.

Huber, O. and Kunz, U. (2007) Time pressure in risky decision-making: effect on risk defusing. Psychology Science, Vol. 49, No. 4, pp 415.

Jack. L. (2015) Food fraud awareness and detection in your business. NSF Food Crime Conference. Available at: http://www.nsf-foodconf.eu/assets/6_food_fraud_awareness_and_detection_ljack.pdf. accessed 2 January 2018.

Johnson, E.J. and Payne, J,W. (1985) Effort and accuracy in choice. Management Sci. Vol. 31, pp 394-414.

Kerstholt, J. (1994) The effect of time pressure on decision-making behaviour in a dynamic task environment. Acta Psychologica, Vol. 86, No. 1, pp 89-104.

Kirby, S. and Nailer, L. (2013) Reducing the offending of a UK organized crime group using an opportunity-reducing framework-a three year case study. Trends in organized crime, Vol. 16, No. 4, pp 397-412.

Kirby, S. and Penna, S. (2010) Policing mobile criminality : towards a situational crime prevention approach to organised crime in $\mathrm{K}$ Bullock, $\mathrm{RV}$ Clarke \& N Tilley.

Klapwijk, C.J., van Wijk, M.T. Rosenstock, T.S. Van Asten, P.J.A. Thornton, P.K. and Giller, K.E. (2014) Analysis of trade-offs in agricultural systems: current status and way forward. Current Opinion in Environmental Sustainability, Vol. 6, pp110-115. 
Kowalska, A., Soon, J.M. and Manning, L., 2018. A study on adulteration in cereals and bakery products from Poland including a review of definitions. Food Control, Vol. 92, pp 348-356

Luce, M.F., Payne, J.W. and Bettman, J.R. (1999) Emotional trade-off difficulty and choice. Journal of Marketing Research, Vol. 36, No.2, pp143159.

Makwasha, T. and Turner, B. (2013) Evaluating the use of rural-urban gateway treatments in New Zealand. Journal of the Australasian College of Road Safety, Vol. 24, No.4, pp14.

Manning, L. (forthcoming) Institute of Food Science and Technology Guide to Good Manufacturing Practice $7^{\text {th }}$ Edition - Manning, L. Eds. ISBN-

Manning, L., Soon. J.M. de Aguiar, L.K. Eastham, J.F. and Higashi, S.Y. (2017) Pressure: driving illicit behaviour in the food supply chain 12th Research Workshop on Institutions and Organisations (12th RWIO) Brazil 1011 July 2017

Manning L. (2016) Food Fraud, policy and food chain, Current Opinions in Food Science, Vol. 10, pp 16-21.

Manning, L. and Soon, J.M. (2016). Food safety, food fraud and food defense: a fast evolving literature, Journal of Food Science, Vol. 81, No. 4, R823-R834

Manning, L., Smith, R. and Soon, J.M. (2016) Developing an Organizational Typology of Criminals in the Meat Supply Chain, Food Policy, Vol. 59, pp 4454.

Manning L., Baines R.N. and Chadd S.A. (2005) Deliberate contamination of the food supply chain, British Food Journal, Vol. 107, No. 4, pp 225-45.

Marvin, H.J., Bouzembrak, Y. Janssen, E.M. van der Fels-Klerx, H.J. van Asselt, E.D. and Kleter, G.A. (2016) A holistic approach to food safety risks: Food fraud as an example. Food Research International, Vol. 89, pp 463-470.

Maule, A.J., Hockey, G.R.J. and Bdzola, L. (2000). Effects of time-pressure on decision-making under uncertainty: changes in affective state and information processing strategy. Acta psychologica, Vol. 104, No. 3, pp 283301.

Mawby, R.I. (2017) 'Defensible Space', in Oxford Research Encyclopedia of Criminology and Criminal Justice. Henry Pontell. New York: Oxford University Press (forthcoming).

McElwee, G., Smith, R. and Lever, J. (2017). Illegal activity in the UK halal (sheep) supply chain: Towards greater understanding. Food Policy, Vol. 69, pp166-175. 
McGloin, J.M., Sullivan, C.J. and Kennedy, L.W. (2011) When Crime Appears:

Mitenius, N., Kennedy, S.P. and Busta, F.F. (2014) Chapter 35 - Food defense, p. 937-958. In Y. Motarjemi and H. Lelieveld (ed.), Food safety management: A practical guide for the food industry, Academic Press, Massachusetts.

Monghasemi, S., Nikoo, M.R. Fasaee, M.A.K. and Adamowski, J. (2015). A novel multi criteria decision making model for optimizing time-cost-quality trade-off problems in construction projects. Expert systems with applications, Vol. 42, No. 6, pp 3089-3104.

Moreto, W.D. and Clarke, R.V. (2013) 11 Script analysis of the transnational illegal market in endangered species. Cognition and Crime: Offender Decision Making and Script Analyses, p.209.

Newman, O. (1972) Defensible space: people and design in a violent city. Macmillan, New York.

NFU Mutual (2017) Rural Crime Now. Rural Crime Report 2017. Available at: https://www.nfuonline.com/nfu-online/news/nfu-mutual-rural-crime-report2017/ (Accessed on 21 May 2018)

NSF (2014) Final report risk modelling of food fraud motivation - NSF Fraud Protection Model intelligent risk model scoping project. Available at: https://www.food.gov.uk/sites/default/files/NSF\%20Final\%20report.pdf. accessed 2 January 2018

O'Connor, A.M., Légaré, F. and Stacey, D. (2003) Risk communication in practice: the contribution of decision aids. BMJ: British Medical Journal, Vol. 327, No. 7417, pp. 736.

Olson, D.L. and Wu, D. (2011) Risk management models for supply chain: a scenario analysis of outsourcing to China. Supply Chain Management: An International Journal, Vol. 16 No. 6, pp 401-408.

PAS 96. (2017) Guide to protecting and defending food and drink from deliberate attack. BSI, London

Perline, I.H. and Goldschmidt, J. (2004) The Psychology and Law of Workplace Violence: A Handbook for Mental Health Professionals and Employers, Charles C Thomas Publisher

Pil, F.K. and Holweg, M. (2006) Evolving from value chain to value grid. MIT Sloan management review, Vol. 47, No. 4, pp 72.

Power, M. (2013) The apparatus of fraud risk. Account. Org. Soc. Vol. 38, pp 525-543. 
870 Prendergast, C. (2002) The tenuous trade-off between risk and

871 incentives. Journal of political Economy, Vol. 110, No. 5, pp 1071-1102.

872

873

874

875

876

877

878

879

880

881

882

883

884

885

886

887

888

889

890

891

892

893

894

895

896

897

898

899

900

901

902

903

904

905

906

907

908

909

910

911

912

913

914

915

916

917
RASFF. Portal (2018) The Rapid Alert System for Food and Feed. Available at: https://ec.europa.eu/food/sites/food/files/safety/docs/rasff. (accessed 2 January 2018)

RASFF (2018) The Rapid Alert System for Food and Feed. Conclusions from the Ministerial Conference on the follow up of the fipronil incident. Brussels, 26 September 2017 Available at:

https://ec.europa.eu/food/sites/food/files/safety/docs/rasff_fipronil-

incident_conclusions_201709.pdf (accessed 2 January 2018)

Read, T. and Tilley, N. (2000). Not rocket science. Problem-solving and crime reduction. ISBN 1-84082-494-8

Reynald, D.M. (2009) Guardianship in action: Developing a new tool for measurement. Crime Prevention and Community Safety, Vol. 1, No. 1, pp 120.

Roy, H.E., Peyton, J. Aldridge, D.C. Bantock, T. Blackburn, T.M. Britton, R. Clark, P. Cook, E. Dehnen-Schmutz, K. Dines, T. and Dobson, M. (2014) Horizon scanning for invasive alien species with the potential to threaten biodiversity in Great Britain. Global Change Biology, Vol. 20, No. 12, pp 38593871.

Sarkis, J., Gonzalez-Torre, P. and Adenso-Diaz, B. (2010) Stakeholder pressure and the adoption of environmental practices: The mediating effect of training. Journal of Operations Management, Vol. 28, No. 2, pp 163-176.

Shugan, S.M. (1980) The cost of thinking. Journal of consumer Research, Vol. 7, No. 2, pp 99-111.

Smith, R. (2017) Documenting entrepreneurial opportunism in action: A case study of sheep theft in the UK from a food supply chain perspective. British Food Journal. Vol. 119, No. 1, pp 105-121.

Smith, R., McElwee, G. and Somerville, P. (2017a) Illegal diversification strategies in the farming community from a UK perspective. Journal of Rural Studies, Vol. 53, pp122-131.

Smith, R., Manning, L. and McElwee, G. (2017b) Critiquing the InterDisciplinary Literature on Food-Fraud, International Journal of Rural Criminology, Vol. 3, No. 2, pp 250 - 270

Smith, R. and McElwee, G. (2017) Illegal activity in the Horse Meat' Supply Chain: Understanding Food Fraud in the context of the 2013 Horsemeat Scandal, ISBE, Belfast, 8-9 November, 2017. 
Smith, R. (2010), Policing the changing landscape of rural crime: a case study from Scotland, International Journal of Police Science \& Management, Vol. 12 No. 3, pp. 373-387.

Soon, J.M. and Manning L. (2017) Whistleblowing as a countermeasure strategy against food crime, British Food Journal, Vol. 119, No. 12, pp 1-25

Spink, J., Moyer, D.C. and Whelan, P. (2016). The role of the public private partnership in Food Fraud prevention-includes implementing the strategy. Current Opinion in Food Science, Vol. 10, pp 68-75.

Spink, J., Moyer, D.C. Park, H. Wu, Y. Fersht, V. Shao, B. Hong, M. Paek, S.Y. and Edelev, D. (2015) Introduction to Food Fraud including translation and interpretation to Russian, Korean and Chinese languages. Food Chemistry. Vol. 189, pp 102-107.

Spink, J., Ortega, D.L. Chen, C. and Wu, F. (2017) Food fraud prevention shifts the food risk focus to vulnerability. Trends in Food Science and Technology, Vol. 62, pp 215-220.

Spink, J. and Moyer, D.C. (2013) Understanding and combating food fraud, Food Technology, Vol. 67, No. 1, pp 30-35.

Spink, J. and Moyer, D.C. (2011) Defining the public health threat of food fraud. Journal of Food Science, Vol. 76, No. 9, pp 157-163

Spink, J. (2011) The challenge of intellectual property enforcement for agriculture technology transfers, additives, raw materials, and finished goods against product fraud and counterfeiters. J. Intellect. Prop. Rig. Vol. 16, No. 2, pp 183-193.

Stanley, M.C., Beggs, J.R. Bassett, I.E. Burns, B.R. Dirks, K.N. Jones, D.N. Linklater, W.L. Macinnis-Ng, C. Simcock, R. Souter-Brown, G. and Trowsdale, S.A. (2015) Emerging threats in urban ecosystems: a horizon scanning exercise. Frontiers in Ecology and the Environment, Vol. 13, No. 10, pp 553560.

van Ruth, S.M., Huisman, W. and Luning, P.A. (2017) Food fraud vulnerability and its key factors. Trends in Food Science \& Technology, Vol. 67, pp 70-75.

Yaniv, I. and Foster, D.P. (1995) Graininess of judgment under uncertainty: An accuracy-informativeness trade-off. Journal of Experimental Psychology: General, Vol. 124, No. 4, pp 424.

Yakovleva, N. and Flynn, A. (2004) Innovation and sustainability in the food system: A case of chicken production and consumption in the UK. Journal of Environmental Policy \& Planning, Vol. 6, No (3-4), pp 227-250.

Weisel, D.L. (2003) The sequence of analysis in solving problems. Crime prevention studies, Vol. 15, pp 115-146. 
WHO. 2002. Food safety issues: terrorist threats to food: guidance for establishing and strengthening prevention and response systems 2002.

971 Switzerland. ISBN 9241545844.

972 Winter, S., Berente, N. Howison, J. and Butler, B. (2014) Beyond the 973 organizational 'container': Conceptualizing 21st century sociotechnical work. Information and Organization, Vol. 24, No. 4, pp 250-269.

Wolfe, D.T. and Hermanson, D.R. (2004) The Fraud Diamond: Considering 978 the Four Elements of Fraud. CPA Journal, Vol. 74, No. 12, pp 38-42. 
Table 1. Types of Trade-off (Adapted from Klapwijk et al, 2014)

\begin{tabular}{|l|l|}
\hline Trade off & Examples \\
\hline Field level & $\begin{array}{l}\text { Production yields versus nitrate/phosphate leaching and } \\
\text { water quality }\end{array}$ \\
\hline Enterprise level (crop or animal) & $\begin{array}{l}\text { Grain versus crop residue } \\
\text { Milk versus meat production }\end{array}$ \\
\hline Farm/agricultural system level & $\begin{array}{l}\text { Cropping plans/enterprise mix } \\
\text { Diversification } \\
\text { Maximising short-term versus long-term return }\end{array}$ \\
\hline $\begin{array}{l}\text { Landscape level (agricultural } \\
\text { system versus spatial, } \\
\text { environmental or socio-cultural } \\
\text { objectives }\end{array}$ & $\begin{array}{l}\text { Land use and ecosystem services } \\
\text { Water use }\end{array}$ \\
\hline Supply chain & $\begin{array}{l}\text { Specification versus food waste } \\
\text { Cost versus risk }\end{array}$ \\
\hline
\end{tabular}

980

981

982

983

984

985 


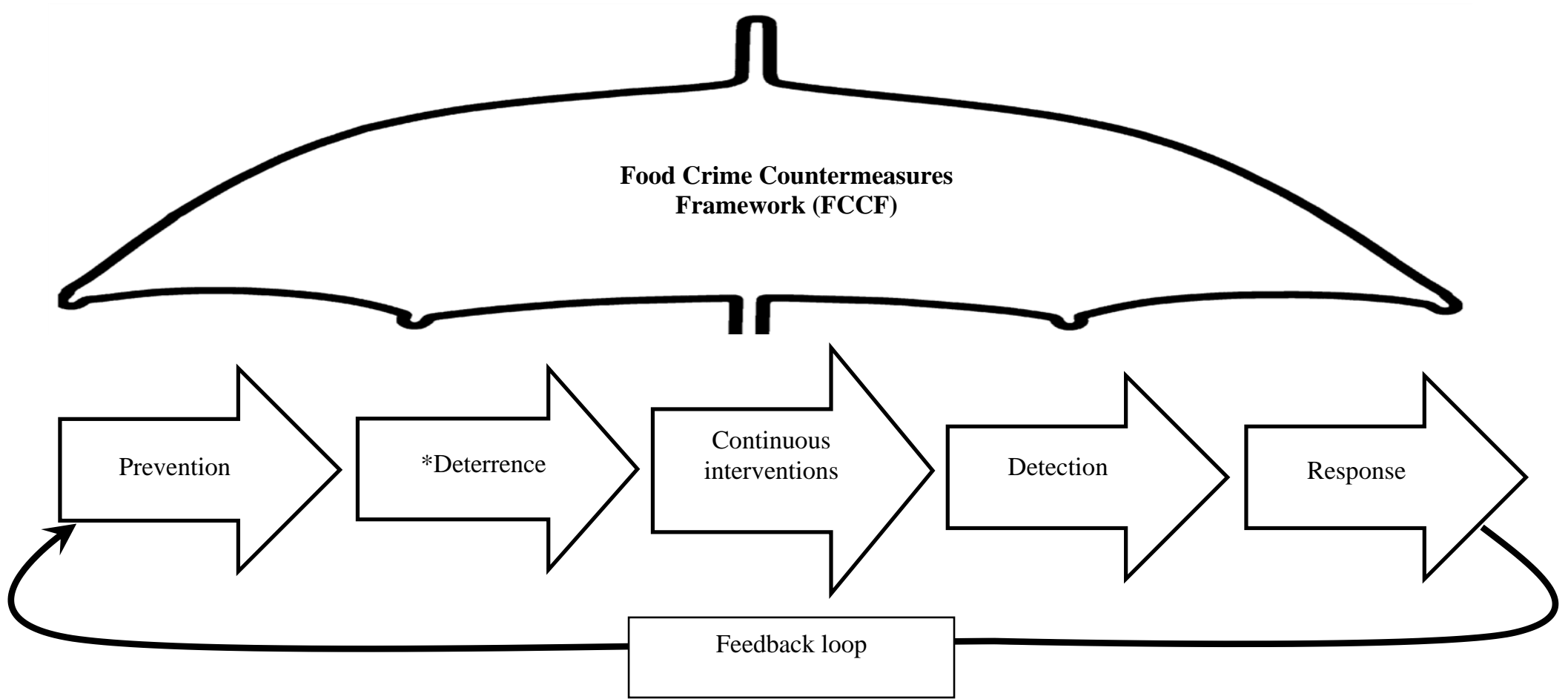

FIGURE 1. Steps in developing a food crime countermeasures framework (FCCF). *Via food crime risk assessment (FCRA), known threats may be prevented, deterred or detected. Via continuous interventions including horizon scanning, existing and emerging threats may be identified or detected and appropriate actions (response) can be taken. 


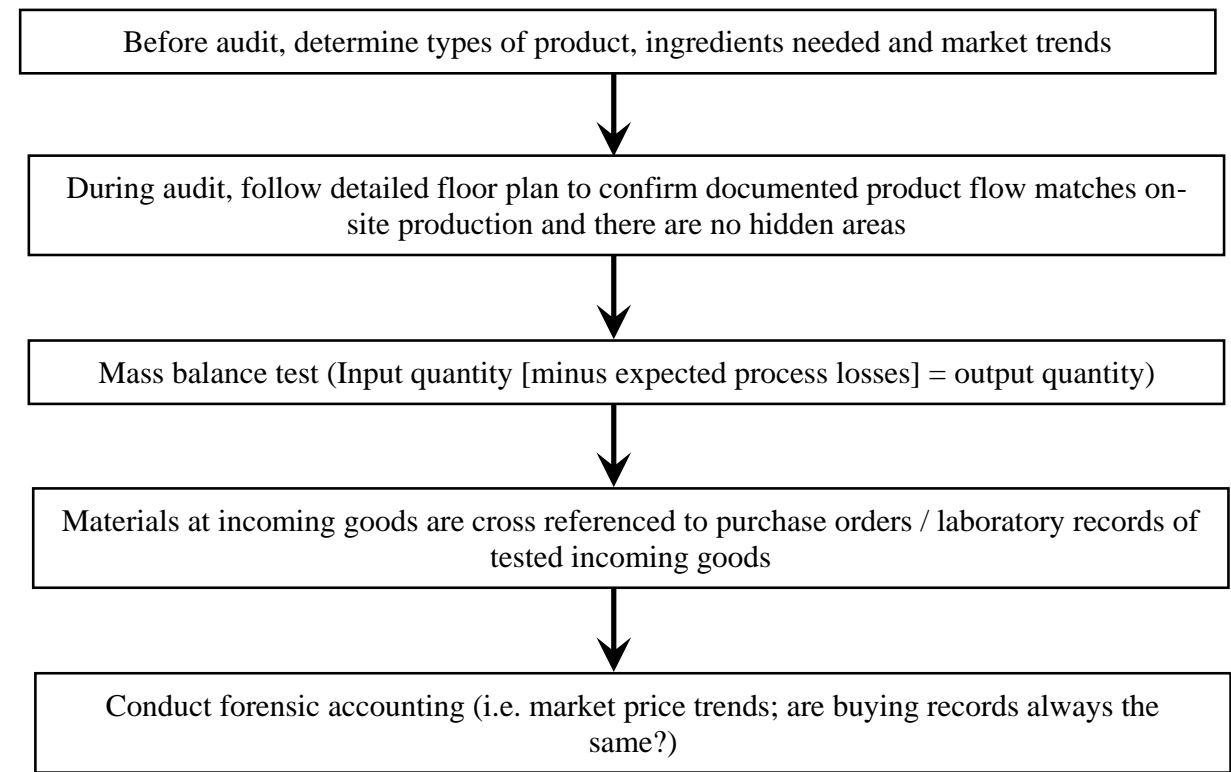

FIGURE 2. Forensic accounting and food crime prevention audits (adapted from Jack, 2015; NSF 2014) 